\title{
Study on the effects and changes of soil degradation under the influence of antibiotics
}

\author{
Ancuta Alexandra Petre $^{1, *}$, Florin Nenciu ${ }^{1}$, Nicoleta Alexandra Vanghele $^{1}$, \\ Mariana Mădălina Stanciu", Dumitru Bogdan Mihalache ${ }^{1}$, Iulia Andreea Grigore $^{1}$ and \\ Laurențiu Vladuțoiu ${ }^{1}$ \\ ${ }^{1}$ INMA National Institute of Research - Development for Machines and Installations designed to \\ Agriculture and Food Industry, Bucharest
}

\begin{abstract}
The use of antibiotics in large quantities against the combat of pests in soils, indicates an increased remanence of them, which leads to major environmental risks. After entering in the soil, antibiotics are subjected to a succession of biogeochemical processes under the action of multiple environmental factors: absorption, migration, transformation, degradation or nutritional prosperity of plants.

In order to know the current state of the environment and the effects of antibiotics it is essential to discover procedures for improving the degradation and combating the dissemination of antibiotic resistance.

Research in recent years on the extraction of antibiotics from the soil is based on complex processes, such as: Soxhlet extraction, ultrasonic extraction or accelerated solvent extraction.

Soil residue was determined using liquid chromatography coupled with mass spectrometry, being the equipment that provides the highest accuracy in the analysis of polar compounds in very low concentrations.

The purpose of the paper is to find an efficient and ecological solution for the elimination of antibiotics from soils and to highlight the evaluation of the contaminated land regarding the antibiotic residues and the impact on the composition of the bacterial community. Information about the effects of antibiotics accumulated in soil, persistence, resistance and sensitivity to chemical and microbiological substances, degradation and results related to soil fertility and crop production are highlighted.
\end{abstract}

Key words: soil, antibiotics, degradation, effect

\section{Introduction}

Emerging contaminants such as pharmaceuticals, personal care products, surfactants, plasticizers or pesticides are pollutants resulted from various anthropogenic activities, that are generating high levels of risk to the environment and human health.

Unlike other contaminants, they have complex structures that make them difficult to trace and remove and they cannot be monitored or decontaminated by classical waste management methods.

Antibiotics are considered by many researchers among the most important discoveries from history, due to the revolutionary contribution they have in human treatment. In

*Corresponding author : ancapetre28@gmail.com 
developing countries, antibiotic use has contributed to increasing life longevity by reducing mortality caused by bacterial infections. However, antibiotics have begun to be considered an increasing threat, on the one hand because they have accumulating effects and on the other hand caused by the impossibility of evaluating in a manner the long-term effects.

These pharmaceuticals are released partially degraded or non-degraded in the environment, creating pollution with antibiotics. Bioremediation could have an important role in the treatment of these group of pollutants, being one of the few solutions that can be applied to such a complex problem [2].

Antibiotic amounts eliminated as residues in nature have too low to kill bacteria, causing microorganisms to adapt to these drugs and to gain certain levels of resistance to them.

When they reach the aquatic and terrestrial ecosystems, antibiotics as microcontaminants show a high risk to human and animal health, due to the fact that may develop multi-resistant and very difficult to treat bacteria [1].

Numerous efforts have been made at EU level to reduce the negative effect of antibiotics ; however, it is still an important problem since antibiotic resistance in microorganisms has increased in the last years. Unfortunately, the development of new therapies and drug formulas that take into account the adaptations of bacteria to current treatments occur over long periods of time [3].

Antibiotics are classified as natural, synthetic and semi-synthetic compounds that interrupt antimicrobial activity [4]. Antibiotics have the most important role from the pharmaceutical spectrum in treating microbial infections having specific therapeutic actions on the targeted patient, as presented in Figure 1. Since 1928 when Alexander Fleming discovered penicillin by mistake, many antibiotics have been synthesized for the use on animal and plant health. Antibiotics may be used as growth promoters in livestock, for example in cattle, pigs and bird preventive treatment to improve feed efficiency [5], although they are banned in the European Union since 2006, they are still in practice in China and India [6]. The widespread use of known antimicrobials in various purposes, for treating animals and plants creates accumulations and important problems for the environment and natural ecosystem [7].

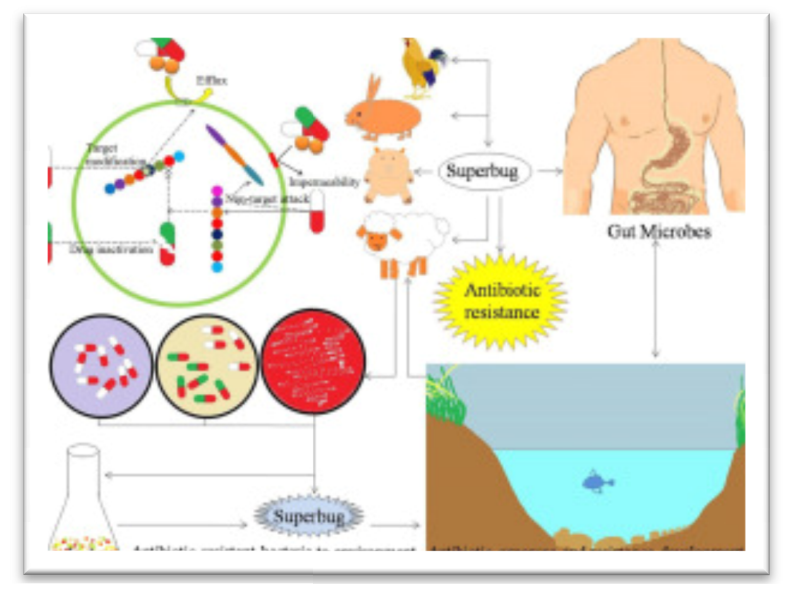

Fig. 1. Antibiotic resistance in the human body, soil and water [1]

Recent studies have been developed regarding synthesized of artificial antibiotics, considering the resistance acquired by some bacteria to main two antibiotics used on large scales, namely penicillin and streptomycin [8]. Overuse, or improper use of antibiotics determines the appearance of microbial resistance, especially in bacterial communities, 
main reason for that being dosing long-term administration of low antibiotic concertation [9].

Antibiotic resistance is the increase of the MIC (minimum inhibitory concentration) when treating against microbes, which prevents visible growth of a bacteria. It is a mechanism by which bacteria can survive the stress of antibiotics. Microbes can exert antibiotic resistance by passing drug targeted interaction, efflux of antibiotics from the cell (TolC efflux pump in E. coli), alteration of antibiotics and their metabolites by enzymes $[10,11]$.

The co-substrate-assisted antibiotic-modifying enzymes, with the help of ATP being a process of rapidly measuring actively growing microorganisms through detection of adenosine triphosphate, can transfer functional groups that covalently modify antibiotics by acetylation, phosphorylation, adenylation, nucleotidylation, ribosylation, and glycosylation [12].

\section{Materials and method}

Biodegradation of antibiotics takes place through two biotic and abiotic processes. Biotic biodegradation requires the use of microorganisms while the abiotic biodegradation requires processes such as sorption, hydrolysis, photolysis, oxidation and reduction reactions [13]. In order to treat terrestrial and aquatic contamination, several microbial populations are analyzed, that might help in elimination of commonly used antibiotics.

In order to evaluate the concentration of residual antibiotics, there have been developed so called biomonitoring tools. These tools include Biomonitoring and Biosensors, Bioassays, biomarkers, and microbial community analyses, all these being constituted with the purpose of reducing and regulating the concentration of these difficult to quantify pollutants. In addition, an environmental monitoring and screening can be acquired, using customized sensors developed to determine some analytes and validate the used models.

The bioremediation process can be described as the metabolic potential that some microorganisms have in disintegrating some pharmaceuticals [14].

Biological methods for the removal of antibiotics are safe and efficient, because they do not employ dangerous and sophisticated treatment procedures, using mostly only bacteria, fungi, nutrients and stabilizing agents.

Another bioremediation important aspect is that can at the same time treat a wide range of other pollutants in addition to antibiotics, improving the health of the soil without having major negative effects.

Metagenomics is a novel technology made for studying genetic material, isolated from environmental samples in order to reveal the knowledge on microbial communities. These techniques could be successfully used for the identification of novel bacteria or gene clusters encoding for enzymes that degrade pollutants, and could be associated to the bioremediation processes.

Antibiotics can also have negative affect on some useful natural microbial communities. These good microbial communities are useful to ecological processes, because they are maintaining soil and water quality, being involved in the biogeochemical natural cycle of organic degradation. Antibiotics present in the environment can therefore affect both longterm and short-term microbial activities.

Indirect impact of antibiotics consist in the evolution of antibiotic resistant bacteria. Using some biodegradation processes, could remove the pollutant from the environment, when mineralized [1].

When using manure as fertilizer there is a risk of contamination with antibiotics from animal farms. Animals release $30 \%-90 \%$ of antibiotics that are ingesting by urine and manure. 
With the application of fertilizer to provide nutrients, can be introduced into the soil and aquatic environments important antibiotic residues, such as TCs (tetracyclines) that are very persistent in the soil. The most commonly found antibiotics in fertilized soils with manure are mainly TC [15]. Antibiotics are mainly classified into different classes such as $\beta$ lactams, tetracyclines, aminoglycosides, macrolides, sulfonamides, antifungal antibiotics $[16,17]$.

A classification of antibiotics according to several requirements was summarized in the table 1, depending on some functional groups, activity mechanisms, molecular weight, etc. [18].

Table 1. Classification of antibiotics [33]

\begin{tabular}{|c|c|c|c|c|c|c|c|}
\hline Class & Antibiotic & $\begin{array}{l}\text { Chemical } \\
\text { formula }\end{array}$ & \begin{tabular}{|l|} 
Molecul \\
ar \\
weight \\
(g/mol)
\end{tabular} & \begin{tabular}{|l|} 
Water \\
solubilit \\
y \\
$(\mathrm{mg} / \mathrm{L})$
\end{tabular} & $\begin{array}{l}\mathrm{Log} \\
\mathrm{KO} \\
\mathrm{W}\end{array}$ & \begin{tabular}{|l|}
$\mathrm{Kd}$ \\
$(\mathrm{L} / \mathrm{kg})$
\end{tabular} & $\begin{array}{l}\text { KOC } \\
(\mathrm{L} / \mathrm{kg})\end{array}$ \\
\hline \multirow[t]{2}{*}{ Aminoglycosides } & Gentamicin & $\mathrm{C} 21 \mathrm{H} 43 \mathrm{~N} 5 \mathrm{O} 7$ & 477.6 & 100,000 & -3.1 & - & - \\
\hline & Streptomycin & C21H39N7O12 & 581.6 & 12,800 & -6.4 & $8-290$ & \begin{tabular}{|l}
$580-$ \\
11,000 \\
\end{tabular} \\
\hline \begin{tabular}{|l}
$\begin{array}{l}\text { Diaminopyrimidi } \\
\text { nes }\end{array}$ \\
\end{tabular} & Trimethoprim & C14H18N4O3 & 290.3 & 400 & 0.91 & 7.40 & 4,600 \\
\hline \multirow[t]{5}{*}{ Fluoroquinolones } & Ciprofloxacin & C17H18FN3O3 & 331.3 & 30,000 & 0.28 & $\begin{array}{l}427- \\
4,844 \\
\end{array}$ & \begin{tabular}{|l}
$1,127-$ \\
61,000 \\
\end{tabular} \\
\hline & Difloxacin & $\mathrm{C} 21 \mathrm{H} 19 \mathrm{~F} 2 \mathrm{~N} 3 \mathrm{O} 3$ & 399.4 & 1,330 & 0.89 & - & - \\
\hline & Enrofloxacin & C19H22FN3O3 & 359.4 & $>53.9$ & 0.7 & $\begin{array}{l}0.54- \\
5,612\end{array}$ & \begin{tabular}{|l}
$39-$ \\
768,74 \\
0 \\
\end{tabular} \\
\hline & Norfloxacin & C16H18FN3O3 & 319.3 & 177,900 & \begin{tabular}{|l}
-1.0 \\
3 \\
\end{tabular} & \begin{tabular}{|l}
$591-$ \\
5,791 \\
\end{tabular} & 310 \\
\hline & Ofloxacin & C18H20FN3O4 & 361.4 & 10,800 & 0.35 & $1,471-$ & 44,140 \\
\hline Glycopeptides & Vancomycin & $\begin{array}{l}\text { C66H75Cl2N9O } \\
24\end{array}$ & 1449.3 & $>1,000$ & $\mid-3.1$ & $0.3-$ & - \\
\hline \multirow[t]{2}{*}{ Ionophores } & Lasalocid & C34H54O8 & 590.8 & 750 & - & $9-280$ & $\begin{array}{l}2.9- \\
4.2 \\
\end{array}$ \\
\hline & Monensin & C36H62O11 & 670.9 & 0.003 & 5.43 & $0.5-65$ & \begin{tabular}{|l}
$2.1-$ \\
3.8
\end{tabular} \\
\hline \multirow[t]{4}{*}{$\beta$-Lactams } & Amoxicillin & C16H19N3O5S & 365.4 & 3,430 & 0.87 & - & 865.5 \\
\hline & Cephapirin & C17H17N3O6S2 & 423.5 & 1,030 & \begin{tabular}{|l}
-1.1 \\
5
\end{tabular} & \begin{tabular}{|l}
$0.21-$ \\
3.83 \\
\end{tabular} & $\mid-$ \\
\hline & Cefuroxime & C16H16N4O8S & 424.4 & 145 & \begin{tabular}{|l|}
-0.1 \\
6
\end{tabular} & - & \begin{tabular}{|l|}
$2.4-$ \\
15.5 \\
\end{tabular} \\
\hline & Penicillin G & C16H18N2O4S & 334.4 & 210 & 1.83 & - & 2.68 \\
\hline \multirow[t]{2}{*}{ Lincosamides } & Clindamycin & $\begin{array}{l}\mathrm{C} 18 \mathrm{H} 33 \mathrm{ClN} 2 \mathrm{O} 5 \\
\mathrm{~S}\end{array}$ & 424.9 & 30.6 & 2.16 & - & 70 \\
\hline & Lincomycin & C18H34N2O6S & 406.5 & 927 & 0.2 & - & 59 \\
\hline \multirow[t]{2}{*}{ Macrolides } & Azithromycin & C38H72N2O12 & 748.9 & 2.37 & 4.02 & 2.18 & 59,900 \\
\hline & Clarithromycin & C38H69NO13 & 747.9 & 1.7 & 3.16 & $\begin{array}{l}262- \\
400\end{array}$ & 150 \\
\hline
\end{tabular}




\begin{tabular}{|c|c|c|c|c|c|c|c|}
\hline Class & Antibiotic & \begin{tabular}{|l} 
Chemical \\
formula
\end{tabular} & \begin{tabular}{|l} 
Molecul \\
ar \\
weight \\
$(\mathrm{g} / \mathrm{mol})$
\end{tabular} & \begin{tabular}{|l|} 
Water \\
solubilit \\
y \\
$(\mathrm{mg} / \mathrm{L})$
\end{tabular} & $\begin{array}{l}\mathrm{Log} \\
\mathrm{KO} \\
\mathrm{W}\end{array}$ & $\begin{array}{l}\mathrm{Kd} \\
(\mathrm{L} / \mathrm{kg})\end{array}$ & \begin{tabular}{|l}
$\mathrm{KOC}$ \\
$(\mathrm{L} / \mathrm{kg})$
\end{tabular} \\
\hline & Erythromycin & C37H67NO13 & 733.9 & 2,000 & 3.06 & 130 & 10 \\
\hline & Tylosin & C46H77NO17 & 916.1 & 5,000 & 1.63 & \begin{tabular}{|l}
$5.4-$ \\
172,48 \\
0
\end{tabular} & \begin{tabular}{|l}
$110-$ \\
95,532
\end{tabular} \\
\hline \multirow[t]{8}{*}{ Sulfonamides } & $\begin{array}{l}\text { Sulfachloropyridazi } \\
\text { ne }\end{array}$ & $\mathrm{C} 10 \mathrm{H} 9 \mathrm{ClN} 4 \mathrm{O} 2$ & 284.7 & 8,200 & 0.31 & $\begin{array}{l}0.90- \\
3.5\end{array}$ & $\begin{array}{l}41- \\
170\end{array}$ \\
\hline & Sulfadiazine & C10H10N4O2S & 250.3 & 77 & $\begin{array}{l}-0.0 \\
9\end{array}$ & $\begin{array}{l}1.40- \\
14\end{array}$ & $\begin{array}{l}37- \\
125\end{array}$ \\
\hline & Sulfadimethoxine & C12H14N4O4S & 310.3 & 343 & 1.63 & $\begin{array}{l}0.7- \\
4.60\end{array}$ & $\begin{array}{l}89- \\
323\end{array}$ \\
\hline & Sulfadoxine & C12H14N4O4S & 310.3 & 2700 & 0.7 & $\begin{array}{l}0.6- \\
4.9\end{array}$ & $\begin{array}{l}1.8- \\
31.3 \\
\end{array}$ \\
\hline & Sulfamethoxazole & C10H11N3O3S & 253.3 & 610 & 0.89 & $\begin{array}{l}0.6- \\
4.9\end{array}$ & \begin{tabular}{|l}
$1.2-$ \\
94.9 \\
\end{tabular} \\
\hline & Sulfamethazine & C12H14N4O2S & 278.3 & 1,500 & 0.89 & \begin{tabular}{|l}
$0.23-$ \\
206
\end{tabular} & \begin{tabular}{|l}
$60-$ \\
208
\end{tabular} \\
\hline & $\begin{array}{l}\text { Sulfamonomethoxi } \\
\text { ne }\end{array}$ & C11H12N4O3S & 280.3 & 10,000 & 0.70 & $\begin{array}{l}0.6- \\
4.9\end{array}$ & $\begin{array}{l}60- \\
200\end{array}$ \\
\hline & Sulfapyridine & C11H11N3O2S & 249.3 & 268 & 0.35 & $\begin{array}{l}1.60- \\
7.40\end{array}$ & $\begin{array}{l}80- \\
308\end{array}$ \\
\hline \multirow[t]{4}{*}{ Tetracyclines } & Chlortetracycline & $\mathrm{C} 22 \mathrm{H} 23 \mathrm{ClN} 2 \mathrm{O} 8$ & 478.6 & 630 & \begin{tabular}{|l}
-0.6 \\
2 \\
\end{tabular} & $\begin{array}{l}1,280- \\
2,386\end{array}$ & 794 \\
\hline & Doxycycline & $\mathrm{C} 22 \mathrm{H} 24 \mathrm{~N} 2 \mathrm{O} 8$ & 4444.4 & 630 & $\mid \begin{array}{l}-0.0 \\
2\end{array}$ & - & - \\
\hline & Oxytetracycline & C22H24N2O9 & $4 \overline{460.4}$ & $1,1,000$ & -0.9 & $\begin{array}{l}417- \\
1,026\end{array}$ & $\begin{array}{l}2,872- \\
93,317 \\
\end{array}$ \\
\hline & Tetracycline & $\mathrm{C} 22 \mathrm{H} 24 \mathrm{~N} 2 \mathrm{O} 8$ & 444.4 & 231 & \begin{tabular}{|l}
-1.1 \\
9
\end{tabular} & $\begin{array}{ll}417- \\
1,026\end{array}$ & $\begin{array}{l}400- \\
93,320\end{array}$ \\
\hline
\end{tabular}


Tetracyclines

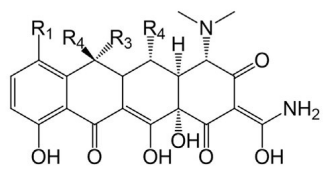

Beta-lactamides<smiles>CC1(C)S[C@@H]2[C@@H](NC(=O)Cc3ccccc3)C(=O)N2[C@H]1C(=O)O</smiles><smiles>C=C(SCC1=C(C(=O)O)N2C(=O)C(NC(=O)/C(=N\OC)c3csc(N)n3)[C@H]2SC1)c1ccco1</smiles>

Diaminopyrimidine<smiles>COc1cc(Cc2cnc(N)nc2N)cc(OC)c1OC</smiles>

*Deoradation nroduct of amoxicillin

\begin{tabular}{clccc}
\hline Compound & $\mathbf{R}_{1}$ & $\mathbf{R}_{2}$ & $\mathbf{R}_{3}$ & $\mathbf{R}_{4}$ \\
\hline Tetracy cline & $\mathrm{H}$ & $\mathrm{CH}_{3}$ & $\mathrm{OH}$ & $\mathrm{H}$ \\
Oxytetracycline & $\mathrm{H}$ & $\mathrm{CH}_{3}$ & $\mathrm{OH}$ & $\mathrm{OH}$ \\
Chlortetracycline & $\mathrm{Cl}$ & $\mathrm{CH}_{3}$ & $\mathrm{OH}$ & $\mathrm{H}$ \\
Doxycycline & $\mathrm{H}$ & $\mathrm{CH}_{3}$ & $\mathrm{H}$ & $\mathrm{OH}$ \\
Demeclocy cline & $\mathrm{Cl}$ & $\mathrm{H}$ & $\mathrm{OH}$ & $\mathrm{H}$ \\
\hline
\end{tabular}

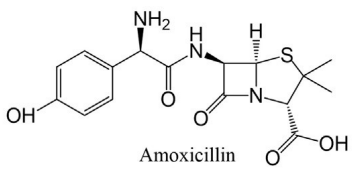

Sulfonamide<smiles>COc1ncnc(NS(=O)(=O)c2ccc(N)cc2)c1OC</smiles>

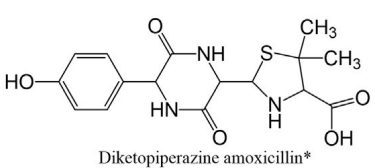

Lincosamide

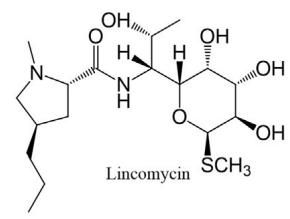

Macrolide

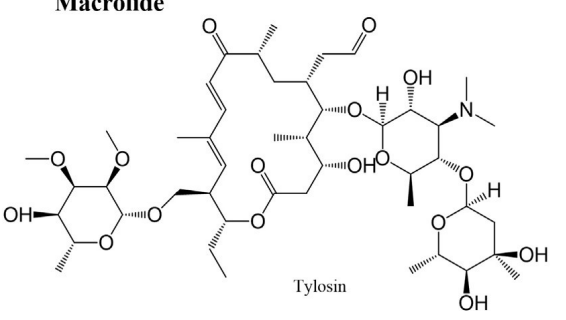

Fig. 2. Chemical structures of some antibiotic structures [33]

Kwon-Rae et al. [19] noted that sludge and manure represent the main source of antibiotics in Korea, due to the long-term use of manure containing antibiotics that accumulates into the soil. He estimated the concentrations of antibiotics total values from animal litter, using studies from the literature on excretion rate of each drug and correlating levels of antibiotic administration on farms

The concentration of macrolides coming from cattle, pigs and birds varied between $0.07-0.14,1.05-2.1$ and $0.62-1.24 \mathrm{mg} / \mathrm{kg}$, while the sulfonamides and tetracyclines were ranged between $0.49,8.44$ and $1.39 \mathrm{mg} / \mathrm{kg}$ and $1.65,16.56$ and $15.62 \mathrm{mg} / \mathrm{kg}$. There are also similar studies with levels of appearance of antibiotics in manure, soil, water and sediments [20-24].

The positive effects of antibiotics are severely reduced after long-term use, that is why quantifying the negative effects is currently of great research interest [25-30]. Considering that most antibiotics are not fully metabolized in the animals bodies, a high percentage of pharmaceuticals are eliminated into municipal wastewater, sewage sludge and with biosolids and reach the soils through irrigation systems, in a cycle similar to the one illustrated in Figure 3 [31,32]. 


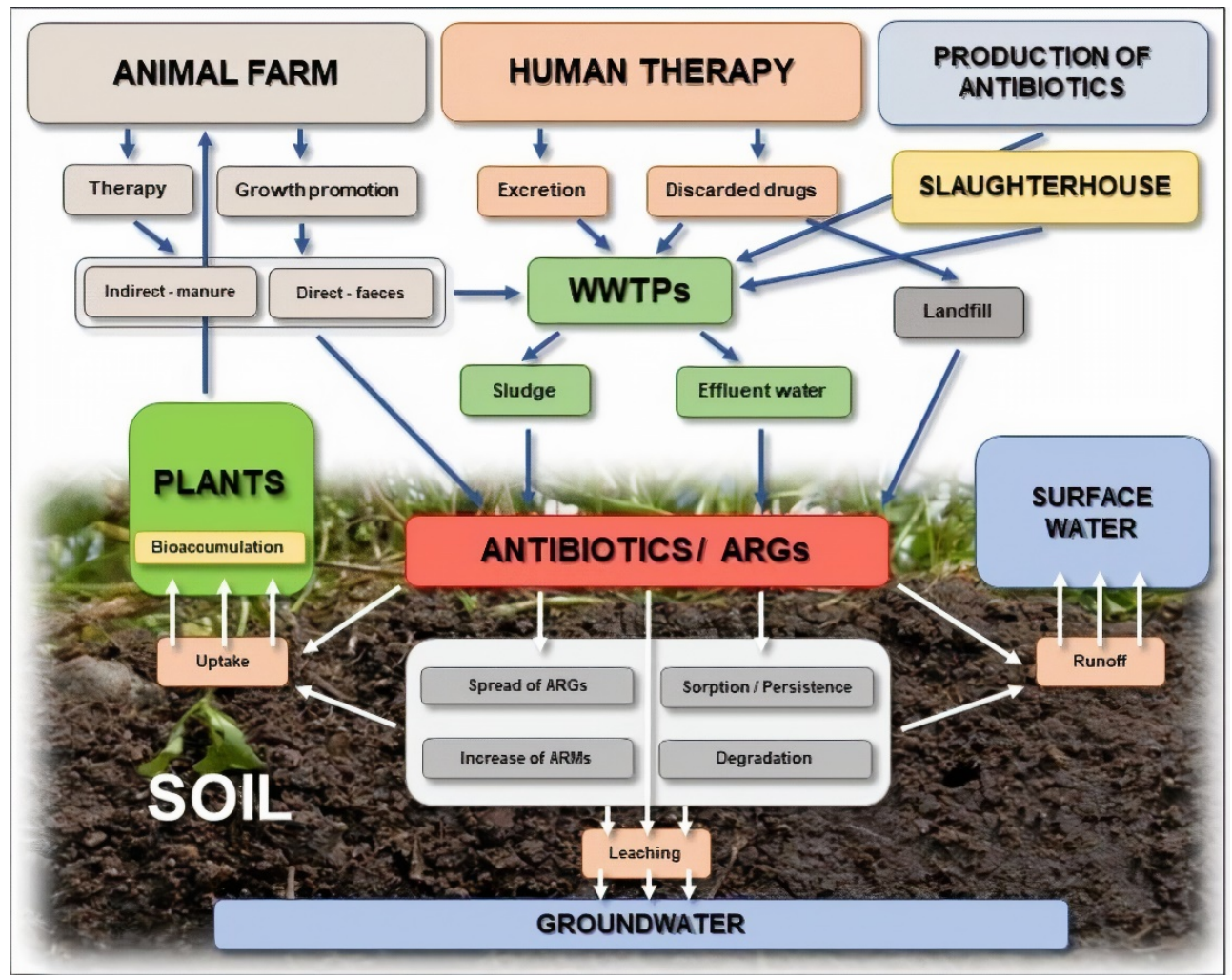

Fig. 3. The life cycle of antibiotics in the environment

\section{Results and discussions}

Sulfonamides are antibacterial substances that are used as antibiotics for the treatment of pigs for fattening or for various infections. Sulfonamides are eliminated then either as a parent compound or as a bioactive metabolite through urine. When fertilizing agricultural soils with manure, the antibiotic residues appear in soils in substantial quantities.

A commonly used substance from sulfonamide class is the sulfadiazine (SDZ). It is recorded that high concentrations of sulfadiazine can affect the structural and functional microbial diversity in soils and negatively affect the ecosystem. Have been assessed in various research studies the extraction of sulfadiazine from soils, using solvents as ethyl acetate, methanol, ethanol/water or acetonitrile/water. The main extraction procedures were stirring extractions, Soxhlet extraction, ultrasonic extraction and accelerated solvent extraction.

Several studies have been made to optimize extraction for residues of sulfadiazine and its two metabolites, $\mathrm{N}$-acetylsulfadiazine and 4-hydroxysulfadiazine from agricultural soil.

The determination of sulfadiazine from soils have been performed using a liquid chromatography - mass spectrometry system (LC-MS), equipment for analyzing polar compounds, the system being shown in Figure 4. 


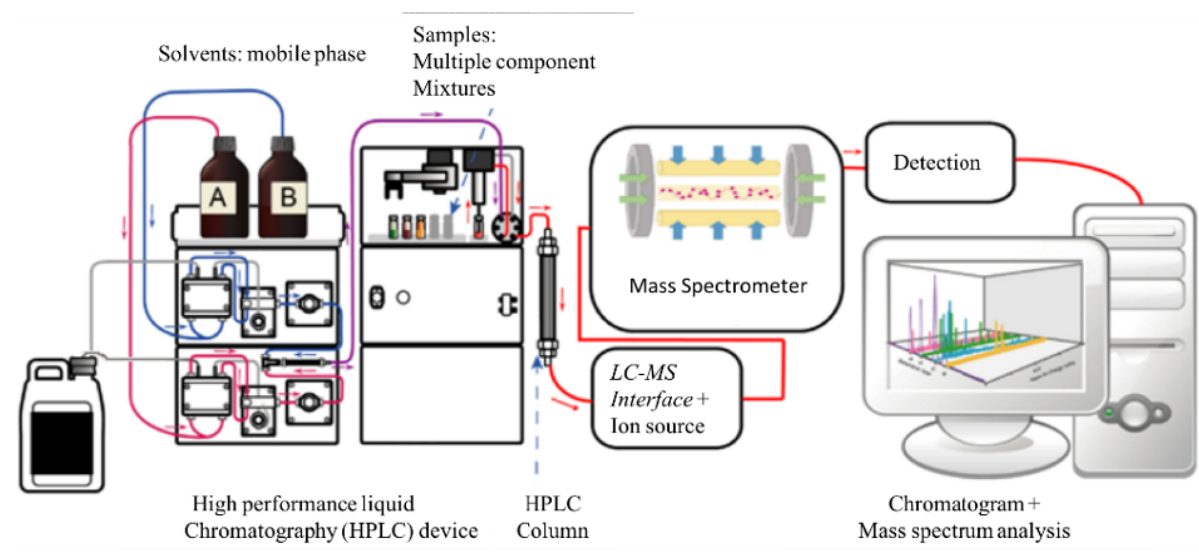

Fig. 4. Diagram of an LC-MS system [34]

Some studies identified correlations between temperatures and the levels of extraction of sulfonamides from the soil [32]. High temperatures corelated with increased $\mathrm{pH}$ values are increasing the degradation of the metabolites of sulfamide acetylate (N-ac-SDZ).

Extraction of sulfamide residues from soils is a difficult task, because of these compounds main characteristics: they are hydrophilic and ionizable in the typical $\mathrm{pH}$ range of soils. Other research studies have been conducted on investigations of the effect of solvent composition, for the extraction of solzidine residues from the soil using a basic extraction procedure.

Treatment of antibiotic residues using composting methods has recently received more interest. Besides the fact that waste is safer, the final composting products contain large amounts of organic matter and mineral nutrients, which could allow its use as an organic fertilizer.

One effective way in reducing the level of persistent organic pollutants and certain antibiotics from soils is composting process. Composting can successfully be used for sludge stabilization, by means of biological degradation of organic matter.

Among the widely used antibiotics, tetracycline family is the most is intensively studied due to high usage rates, followed by sulfonamides, macrolides and fluoroquinolones;

It was deduced from the analysis of several published articles that $82 \%$ of the research studies envisaging composting were performed on a laboratory scale using a reactor, and $18 \%$ were made in piles of compost. Composting is a useful way of reducing tetracycline, sulfonamide and macrolide families, with an elimination rate of $70-99 \%$, while fluoroquinolone family have a clearance rate of up to $99 \%$ for enrofloxacin and norfloxacin.

In some cases, the elimination of antibiotics is correlated with several issues, such as TOC (total organic carbon), total nitrogen, phosphorus, and other trace elements [32].

\section{Conclusions}

Antibiotic control is an extremely important aspect to consider for the authorities and farmers, therefore strict rules are needed when selling these drugs. In addition, clear rules must be imposed on farmers regarding the safe disposal of wastes that may contain traces of antibiotic residues, as well as regarding the use of natural fertilizers in agriculture. 
This bioremediation strategies have proved to be effective ways to decontaminate soils polluted with antibiotics, and bioremediation conditions have been shown to be very important in biological processes.

Bioremediation is suitable for a variety of soil pollutants, other than antibiotics, and have proved a highly potential for cleaning the anthropic ecosystem. That is why in-depth studies are needed for further developing new and improved bioremediation technologies, to address pollutants that are difficult to remedy by other methods.

This work was supported by a grant of the Romanian Education and Research Ministry, through Programme 1 - Development of the national research-development system, subprogramme 1.2 Institutional performance - Projects for financing excellence in RDI, contract no. 16PFE and by a grant of the Ministry of Agriculture and Rural Development, contract of sector financing, ADER type, no. 25.4.1 "Technology for obtaining biofertilizers and/or bioinsecticides, for ecological production systems".

\section{References}

1. P. Grenini, Microchem. J. (2017)

2. M. Kumara et al., Environ Int., 124, 448 - 461 (2019)

3. Walsh et al., Lancet Infect Dis,11,355-362 (2011)

4. L. Catteau et al. 1-35 (2018)

5. A.J. Cowieson et al., Anim.Feed Sci. (2018)

6. M.G.Ronquillo et al. Elsevier Food Control 72, Part B, 255-267 (2017)

7. L. N. Nielsen et al., Environ. Pollut.,233 , 364-376 (2018)

8. J. Lin, Zhou et al., Annu.Rev.Biochem.0 (2018)

9. Wistrand-Yuen,et al., Nat. Commun.9 (1),1599 (2018)

10. V. Kumar. et al., 259-273 (2017)

11. R. Sharma et al., J Environ. Qual, 38, 567-575 (2009)

12. C. Bastos,M. et al., Land Degrad.Dev., 29(8), 2472-2484 (2018)

13. D.I. Massé, Saady et al., Animals 4(2), 146-163 (2014)

14. A.K. Dangi et al., Crit.Rev.Biotechnol, 1-20 (2018)

15. H. Jufer, Pace University, Pleasantville, NY, United States (2018)

16. Z. Shen, Han Nan: Chinese Society of Environ. Sci., 4331-34 (2016)

17. J. Wang and JL J. Gu, "Journal of Livestock and poultry industry", B 10, 8-9 (2017)

18. K. Kümmerer, Part I, Chemosphere, 417-434 (2009)

19. K. Kwon-Rae, G. Owens, S. I. Kwon, K. H. So, D. B. Lee, Y. S. Ok, Water Air Soil Pollut., 214, 163- 174 (2011)

20. X. Li, Y. Xie, J. Wang, G. Christakos, J. Si, H. Zhao, Y. Ding et al., Sci. Total Environ., 63-69 ,458-460, (2013)

21. G. Na, X. Fang, Y. Cai, L. Ge, H. Zong, X. Yuan, Z. Yao et al. , Mar. Pollut. Bull., 69, 233-237 (2013)

22. X. Hu, Q. Zhou, Y. Lou, Environ. Pollut., 158, 2992-2998 (2010)

23. D. R. Lapen, E. Topp, C. D. Metcalfe, H. Li, M. Edwards, N. Gottschall, P. Bolton et al.,Sci. Total Environ., 399, 50-65 (2008)

24. W. Li, Y. Shi, L. Gao, J. Liu, Y. Cai, Chemosphere, 89, 1307-1315 (2012)

25. D. Fatta-Kassinos, I. K Kalavrouziotis, P. H Koukoulakis, M. I. Vasquez, Sci. Total Environ., 409, 3555-3563 (2010)

26. G. Torres-Cortés, V. Millán, H. C Ramírez-Saad., R. Nisa-Martínez, N. Toro, F. Martínez-Abarca, Environ. Microbiol., 13, 1101-1114 (2011)

27. C. Bouki, D. Venieri, E. Diamadopoulos, Ecotoxicol. Environ. Saf. 91 (2013)

28. K. K Brandt, O. R Sjøholm, K. A. Krogh, B. Halling-Sørensen, O. Nybroe, Environ. Sci. Technol., 43, 2963-2968 (2009) 
29. X.-L. Wu, L. Xiang, Q.-Y. Yan, Y.-N. Jiang, Y.-W. Li, X.-P. Huang et al., Sci. Total Environ., 487, 399-406 (2014)

30. D. G.J. Larsson, Ups. J. Med. Sci., 119, 108-112 (2014)

31. R. Daghrir, P. Drogui, Environ. Chem, (2013)

32. K. Stoob., H. P. Singer, S. R Mueller, R. P. Schwarzenbach, C. H. Stamm, Environ. Sci. Technol. 41, 7349-7355 (2007)

33. www.google.com

34. www.wikipedia.org 